\title{
Expectativas y experiencias de un cine marginal (1971-1976)
}

\section{Expectations and Experiences of a Marginal Cinema (1971-1976)}

\author{
Alonso Getino Lima \\ (D) 0000-0002-6343-2287 \\ Escuela Nacional de Antropología e Historia, México \\ agetinolima@gmail.com
}

Resumen: En septiembre de 1971 surgió la Cooperativa de Cine Marginal. Durante el tiempo que estuvo activa (1971-1976) experimentó un proceso de cambio: de ser una organización enfocada al trabajo cinematográfico, se convirtió en un grupo de activistas sindicales. El objetivo de la investigación fue comprender a la Cooperativa en relación con las motivaciones de sus integrantes para constituirla y realizar acciones a través de ella. Trabajando mediante la reconstrucción de sus contextos y procesos personales se concluyó que quienes pertenecieron a la organización transitaron caminos similares de politización. Asimismo, las concepciones adquiridas a la luz de las experiencias de activismo cotidiano fueron factor importante en cuanto a la transformación y fragmentación de la agrupación. Con este estudio se abonó al entendimiento de la década de los setenta en México; un periodo en el que distintos proyectos artísticos, políticos y comunicativos compartieron el escenario social.

Palabras clave: cine; politización; izquierda; historia social; historia oral.

Abstract: The Marginal Film Cooperative emerged in September 1971. During the time it was active (1971-1976), it changed from an organization focused on film work to a group of union activists. The objective of the research was to understand the Cooperative in relation to the motivation of its members to establish it and undertake actions through it. The reconstruction of their contexts and personal processes made it possible to conclude that those who 
belonged to the organization went through similar paths of politicization. Likewise, the conceptions acquired in light of the experiences of everyday activism were an important factor in terms of the group's transformation and fragmentation. This study contributed to the understanding of the 1970s in Mexico, a period when various artistic, political and communicative projects shared the social scene.

Key words: cinema; politicization; left; social history; oral history.

Fecha de recepción: 16 de diciembre de 2016 Fecha de aceptación: 14 de agosto de 2017

\section{INTRODUCCIÓN}

T a Cooperativa de Cine Marginal surgió al concluir el segundo concurso Lde Cine Independiente Luis Buñuel, llevado a cabo en la ciudad de México del 11 al 31 de agosto de 1971. Aquel certamen, organizado por el Comité de Difusión Cultural de la Escuela Nacional de Economía de la UnAm y realizado en las instalaciones del Club de Periodistas y del Instituto Francés de América Latina fue la secuela del emprendido un año antes por el Centro de Arte Independiente las Musas -integrado por Víctor Fosado, Óscar Menéndez, Rubén Gámez, Leopoldo Ayala, Juan de la Cabada y Armando Zayas(Vázquez, 2012, p. 42). La Cooperativa en su origen estuvo constituida por asistentes, participantes y organizadores del mencionado concurso: Ramón Vilar, Víctor Sanen, Enrique Escalona, Gabriel Retes, Paco Ignacio Taibo II, Paco Cantú, Carlos de Hoyos, Carlos Méndez, Jorge Belarmino, Jesús Dávila y Eduardo Carrasco Zanini (Ayala, 1986, p. 381; Vázquez, 2012, p. 197). Sin embargo, en las siguientes semanas y meses, invitados por los fundadores o motivados por sus actividades, se sumaron diversos jóvenes al grupo. Fueron los casos de Guadalupe Ferrer, Héctor Cervera, Paloma Saiz, Servando Gajá, Jesús Brito, Juan Manuel Aurrecoechea, Beatriz Novaro, Santiago I. Flores, Saúl Escobar, Francisco Pérez Arce, David Arriaga Weiss, Luis Hernández Navarro, Gisela Landazurri, Carmen Durán, Horacio Gómez, Nena Cortez, Orlando Delgado, Miguel Lanz, Jorge Fernández Souza, Jorge Robles y Mario Núñez Mariel.

La Cooperativa fue una organización que se caracterizó por articular el cine con la política. Sus miembros habían transitado previamente por

\section{()(1) $(9$}


caminos que abonaron a su politización, en el sentido de que fueron desarrollando a lo largo de las lecturas realizadas y las experiencias vividas una conciencia de su papel y el de otros grupos en la historia. Los cooperativistas se concibieron como acompañantes, asesores e intelectuales orgánicos de los sectores subalternos, especialmente del sector obrero. Su labor, aunque transitó por distintos momentos, estuvo siempre vinculada con estos, preocupándose en mayor medida por construir y fortalecer lazos de solidaridad entre trabajadores de diferentes latitudes del país para edificar un movimiento nacional en favor de la democracia sindical y en general del mejoramiento de sus condiciones de vida. El cine que realizaron fue construido en ese marco, de manera que se trató de un cine documental de carácter informativo, que resultara útil para sus receptores.

La Cooperativa no fue una organización aislada, fue parte de una tendencia de acción para diversos jóvenes después del movimiento estudiantil; así como algunos organizaron guerrillas urbanas, otros se preocuparon por vincular manifestaciones artísticas con intenciones políticas. En los primeros años de la década de los setenta surgieron grupos y organizaciones como el Centro Libre de Experimentación Teatral y Artística, Tepito Arte Acá, Taco de la Perra Brava, Grupo Cine Testimonio, Taller Arte Ideología, Taller de Cine Octubre o Colectivo Cine Mujer, que en dirección similar a la de la Cooperativa de Cine Marginal trabajaron muy de cerca con los sectores subalternos del país, tratando de repercutir positivamente en sus condiciones sociales mediante diversas prácticas artísticas que contribuyeran a su concientización, en el sentido de propiciar su autodefinición dentro de un proceso histórico en el que coexistían distintas clases sociales con intereses encontrados, en concordancia con las lecturas realizadas por los jóvenes activistas de la coyuntura vivida (Híjar, 2007; Gaytán, 2013). En el caso de los cooperativistas, tales interpretaciones impactaron en la transfiguración del perfil de la organización en su conjunto: de ser un grupo de jóvenes enfocados en la labor cinematográfica se convirtió en un colectivo de asesores y activistas sindicales.

Cabe mencionar que este texto forma parte de una investigación más extensa sobre la Cooperativa que realicé desde la óptica de la historia social, entendiéndola como la historia de la sociedad en su conjunto. Es decir, centrando la atención en los sujetos que la constituyeron, insertándolos en sus contextos y procesos particulares. Me basé en los puntos importantes de metodología que para la historia social realizó Eric Hobsbawm: 1) aborda

\section{()(1) $(9$}


el tiempo cronológico; 2) se centra en el estudio de los grupos, sociedades, y 3) su elaboración requiere de un orden en la investigación, identificando prioridades (Hobsbawm, 1983, p. 30). En esta investigación tuve como eje las consideraciones de E. P. Thompson entorno a la experiencia. Este historiador puso en la mesa de la discusión nuevos asuntos, invisibles para la historiografía tradicional marxista de mediados del siglo $\mathrm{xx}$, la cual se caracterizaba por acoplar los datos empíricos a los modelos teóricos de base y superestructura, así como para la historiografía positivista, que abogaba por dejar hablar a los documentos mediante la neutralidad del historiador. Con el trabajo de Thompson se esclareció que la concientización de los hombres no ocurre a partir de moldes establecidos y que es necesario poner el acento en los elementos sociales y culturales propios al interior de los distintos grupos, enfrentados con el mundo mediante la experiencia de cada sujeto y codificados como conciencia (Thompson, 1981, p. 263). En este sentido es significativa la consideración: "El ser social determina la conciencia social", con la que concuerda este autor. Así, la experiencia resulta un fenómeno unificador, para los grupos sociales, en el sentido de que se establece un vínculo entre sus integrantes, o en otros términos una "identidad común de clase", en permanente configuración. De tal manera, partir del análisis de las experiencias posibilita pensar la relación entre ideas y prácticas o motivaciones y acciones en los sujetos. En torno a este asunto radicaron mis intereses de investigación sobre la Cooperativa de Cine Marginal, conformada por una diversidad de jóvenes movilizados ante una situación coyuntural específica.

La investigación se centró en comprender las motivaciones y expectativas que llevaron a los miembros de la organización a integrarse y emprender acciones mediante ella, así como las transformaciones que estas tuvieron a lo largo de los años y que repercutieron en el perfil de la Cooperativa en su conjunto. Aquí presento algunos apuntes al respecto, tratando de sintetizar y subrayar lo que considero más significativo, y dar pauta para seguir con nuevas rutas en el análisis.

Para este trabajo realicé entrevistas a siete integrantes de la Cooperativa, los cuales ingresaron a la organización en distintos momentos: un miembro fundador -Eduardo Carrasco Zanini-, tres que se sumaron pocas semanas después de su constitución -Guadalupe Ferrer, Héctor Cervera y Juan Manuel Aurrecoechea- $y$ tres que ingresaron en un periodo posterior -Santiago I. Flores, David Arriaga y Francisco Pérez Arce-. Cabe señalar

\section{(1)(1) $(9$}


que uno de los criterios selectivos de los entrevistados fue el de captar la heterogeneidad, en cuanto a posturas, al interior de la Cooperativa; encontrando tres tendencias principales: quienes estaban mayormente preocupados por la exhibición y realización de películas -Héctor Cervera, Eduardo Carrasco Zanini-, quienes privilegiaban marcadamente el activismo político sobre el cine-Francisco Pérez Arce, Santiago I. Flores-, y quienes a pesar de haberse abocado mayormente a actividades de organización y activismo con grupos de trabajadores no descartaron la posibilidad de emplear el medio audiovisual para hacer política -Guadalupe Ferrer, David Arriaga, Juan Manuel Aurrecoechea.

Con fines expositivos en el presente ensayo recorreré cuatro momentos: 1) los procesos de politización de los integrantes entrevistados de la Cooperativa, que repercutieron en su decisión de ser parte de la organización; 2) las expectativas que se tenían al interior de la organización en torno al tipo de cine que realizaban; 3) sus discusiones con otras propuestas fílmicas, y 4) los trayectos que recorrió la Cooperativa a lo largo de los años y que fueron marcándola en cuanto a la transformación de sus intereses con respecto a la articulación del cine con la política.

\section{PROCESOS DE POLITIZACIÓN}

Las escuelas fueron los espacios más importantes en cuanto a los procesos de politización de los cooperativistas. En ellas tuvieron contacto con ideas y prácticas que los transformaron, ya sea mediante su adscripción a determinados seminarios, influencia de ciertos profesores, pertenencia a grupos políticos o asistencia regular a los cineclubes organizados en distintos espacios universitarios. En estos lugares, los cooperativistas fueron adquiriendo una visión estructurada de la realidad, una determinada idea de las posibilidades del cine en la sociedad, así como cierta información que fomentaba su sensibilidad en cuanto a los problemas de otros grupos sociales.

Con respecto a este asunto, los testimonios de algunos de los miembros de la organización son significativos. Tal es el caso del de Guadalupe Ferrer -quien fue integrante de la Cooperativa de Cine Marginal desde momentos cercanos a su fundación hasta su fragmentación en 1976-. En cuanto a la importancia de los cineclubes en su etapa de estudiante universitaria, Guadalupe recuerda:

\section{()(1) $(9$}


[...] el cineclub de Filosofía y Letras fue fundamental para que pudiéramos ver una cantidad de cosas enormes. Pero desde Chaplin, que no creas que lo podías ver fácilmente. Desde Tiempos modernos, y además verlo en pantalla grande era padrísimo. Todo el cine cubano. La revolución cubana estaba muy presente. Además, tenía una producción cinematográfica en ese momento fantástica. Memorias del subdesarrollo, Lucía. [...] El cineclub, como tal sí fue un elemento formativo de nuestra educación sentimental, muy importante. [...] El carácter del cineclub asumía un compromiso que era: te voy a presentar una propuesta de películas, o sea, ciclos, en donde lo ideal es que platiquemos qué te pareció. ${ }^{1}$

En torno al mismo asunto Héctor Cervera, estudiante de Veterinaria a inicios de los setenta y también integrante de la Cooperativa en sus primeros meses de existencia, apunta:

Yo no iba a clases de Veterinaria, no me gustaba la veterinaria y me iba o a Políticas, a los seminarios, a las clases que daba el profesor González Pedrero, cualquiera de ellos. Y después me iba al cineclub, a todos los cineclubs. [...] Una de las maneras de aprender a hacer cine fue o haciéndolo o viéndolo. [...] Bergman, Antonioni, Fellini, Godard. [...] Todas las películas que hizo Gillo Pontecorvo: Z [sic] y La Batalla de Argel. ${ }^{2}$

Las escuelas, como se entrevé en el testimonio de Héctor Cervera, constituyeron espacios de formación y activación política para diversos cooperativistas también en cuanto a la influencia de profesores y formación de grupos de estudio. A este respecto el caso de David Arriaga es particularmente significativo:

Veníamos a la Facultad de Economía a los seminarios de El Capital, que daban unos excelentes maestros: Jorge Juanes, Bolívar Echeverría. Gente muy, muy buena. Y entonces nos metíamos de oyentes y participábamos en clase. [...] Pero sí, participábamos. Se establecían relaciones con los maestros que

${ }^{1}$ Ferrer, G. (11 de febrero de 2015). Entrevista a Guadalupe Ferrer/Entrevistador: Alonso Getino Lima, Ciudad de México.

${ }^{2}$ Cervera, H. (17 de febrero de 2016). Entrevista a Héctor Cervera/Entrevistador: Alonso Getino Lima, Ciudad de México. 
fueron más allá de las horas de clase y para profundizar aún más. Ávidos de tragarse el mundo a través de la academia. ${ }^{3}$

David Arriaga estudió la preparatoria en la Escuela Moderna Americana, lugar en el que según refiere, se le introdujo el "virus del comunismo y del socialismo y de la lucha revolucionaria" debido a la influencia de un par de maestros que impartían en aquella institución las clases de Lógica y Física. Fue a partir de entonces que decidió participar en un grupo de estudio de marxismo con jóvenes provenientes de distintas escuelas:

Yo estaba en un pequeño grupo de estudio de compañeros de diferentes escuelas privadas que en ese setenta y, no sé..., creo que fue el 72 [...] teníamos inquietudes alrededor del marxismo y había un grupo de compañeros que estaban estudiando marxismo, gente del Instituto Vives, [...] gente del Colegio Madrid, gente de la Academia Hispano Mexicana y otros. En fin, de varias escuelas, y pues las amistades que teníamos en esos momentos con unos buenos amigos que estaban en este Instituto Vives, conocían a otros y en fin, se organizó este grupo de estudios y, aparte, teníamos también pues inquietudes de participar en el movimiento social, que en ese tiempo había estado muy restringido, había estado muy reprimido, fue en la época que estaba en pleno la guerra sucia contra las organizaciones militares y bueno nosotros pensábamos que la vía era, por la vía no armada. ${ }^{4}$

Estas reflexiones serían las que llevarían en 1973 a David Arriaga a sumarse a la Cooperativa de Cine Marginal. Sin embargo, había realizado actividades de activismo político desde un año antes, motivadas por las discusiones sostenidas dentro del círculo de estudio referido. En aquel momento recuerda David que había una disyuntiva entre los jóvenes en cuanto a continuar dentro de los ámbitos académicos o emprender acciones fuera de las universidades en apoyo a los sectores subalternos. David decidió en aquel momento seguir el segundo camino. De tal manera, con sus compañeros se acercó a los abogados laboralistas Armando Castillejos y Adela Salazar para

3 Arriaga Weiss, D. (20 de abril de 2015). Entrevista a David Arriaga Weiss/Entrevistador: Alonso Getino Lima, Ciudad de México.

4 Arriaga Weiss, D. (20 de abril de 2015). Entrevista a David Arriaga Weiss/Entrevistador: Alonso Getino Lima, Ciudad de México.

\section{(1) (1) $(9$}


hacer trabajo de activismo político. Así refiere sus intenciones con respecto a su actividad con los trabajadores en esos momentos:

Un enfoque de beneficio hacia los trabajadores. [...] En fin, hacerlos conscientes de los derechos acerca de la explotación que sufrían a manos de los patrones y de los charros sindicales..., y apoyarlos en convocar a reuniones con gente que estuviera interesada y hacer un pequeño núcleo que poco a poco fuera trabajando en el interior de la fábrica, etcétera. Y, por otro lado, nos sugirieron [Armando Castillejos y Adela Salazar] apoyar, por ejemplo, la realización de sábados culturales en el local del sindicato independiente [se refiere al de Ánfora]..$^{5}$

Francisco Pérez Arce, quien al igual que David fue integrante de la Cooperativa de Cine Marginal en una etapa tardía, también empezó a realizar actividades políticas a partir de su ingreso a la preparatoria a mediados de la década de los sesenta. En aquel momento formó parte de la Liga Comunista Espartaco, lo cual le posibilitó la consolidación de relaciones sociales estrechas con otros militantes debido al trabajo cotidiano dentro del grupo que se consolidarían aún más a partir del movimiento estudiantil de 1968.

Nosotros éramos militantes desde la prepa [se refiere a él y a Paco Ignacio Taibo II]. Yo estudié en la Prepa Uno y Paco Ignacio y yo éramos compañeros desde primero de prepa. Y cuando entramos a la universidad él, yo y muchos otros compañeros; él entró a la Facultad de Ciencias Políticas y Sociales, yo entré a Economía, mantuvimos una relación muy cercana y amistosa y digamos más de una militancia política pero sobre todo muy amistosa $[. . .]^{6}$

Aunado al factor de la ebullición de ideas progresistas, el ambiente cultural y las prácticas de organización dentro de los colegios a finales de los sesenta e inicios de los setenta, otro factor importante a considerar en cuanto a la politización de los cooperativistas fue el movimiento estudiantil de 1968 , con repunte en junio de 1971. La mayoría de los integrantes de la organiza-

${ }^{5}$ Arriaga Weiss, D. (20 de abril de 2015). Entrevista a David Arriaga Weiss/Entrevistador: Alonso Getino Lima, Ciudad de México.

${ }^{6}$ Pérez Arce, F. (2 de marzo de 2016). Entrevista a Francisco Pérez Arce/Entrevistador: Alonso Getino Lima, Ciudad de México.

\section{(1) (1)}


ción entrevistados participaron en él y sus experiencias entorno al mismo resultaron un elemento trascendental en sus vidas. Concibieron entonces la necesidad de llevar esa experiencia a otros ámbitos, mediante el apoyo y asesoramiento de grupos de colonos, obreros y campesinos. En tal sentido, resulta pertinente la afirmación de Armando Bartra de que a partir del movimiento estudiantil en México se evidenció una nueva izquierda, constituida por jóvenes estudiantes que en contraposición a la existente en aquel momento, representada sobre todo por el Partido Comunista Mexicano, tuvo mayor participación y sensibilidad ante los problemas de los grupos mencionados, siendo uno de sus aspectos más importantes la intención de establecer relaciones horizontales con los trabajadores (Bartra, 2009, p.72). La Cooperativa de Cine Marginal formó parte de este nuevo sector que como refiere Quiroz Trejo se caracterizó por el propósito de continuar el movimiento estudiantil a través del activismo cotidiano; se trató de una postura que, en contraposición a las prácticas de la vieja izquierda, pretendía ser "heterodoxa, autónoma, antiautoritaria, hedonista, libertaria y plural" (Quiroz, 2010, p. 74). En los relatos de los cooperativistas es posible visualizar el impacto que en dicho sentido el movimiento estudiantil tuvo en sus vidas, repercutiendo en su decisión de convertirse en realizadores comprometidos con lo político y activistas sociales. Guadalupe Ferrer, en torno a esto menciona:

El 68 fue muy importante porque no sólo fue una concientización de los jóvenes que nos involucramos en esto, para entender un poco de qué iba la cosa en el mundo. [...]De pronto, a esa edad podías ya empezarte a hacer dueño de tu vida. Estaba toda la influencia del rock, que era importante. Había un gran movimiento cinematográfico. Estaba la nueva ola, pero muchas otras cosas también. [...]Pero, aquí el mundo se ampliaba enormemente, a los libros y a la música, pero sobre todo, a través del cine, de las propuestas cinematográficas que estaban irrumpiendo. Todo eso, pues era un mundo muy atractivo. De pronto sí te sentías muy protagonista. Y el 68 hizo que uno se sintiera protagonista, [...] la historia en la facultad dentro de la huelga pues es importantísima. Ahí sí, círculos de estudio, o sea..., contactos, aprender a ir a hablar a los mercados, a los camiones. O sea, a hablarle a la gente. ${ }^{7}$

${ }^{7}$ Ferrer, G. (27 de enero de 2016). Entrevista a Guadalupe Ferrer/Entrevistador: Alonso Getino Lima, Ciudad de México.

\section{()(1) $(3$}


Una lectura similar del movimiento estudiantil como un parteaguas en la vida, es realizada por Francisco Pérez Arce:

Cuando estalló el 68. Nosotros entramos a la Universidad, a CU, en el 68. Entonces estábamos en esa, digamos vida universitaria más o menos tranquila, con una militancia de izquierda, en una organización que era la Liga Comunista Espartaco. Es la organización del espartaquismo. [...] Y cuando surgió el movimiento del 68 de pronto nos vimos inmersos en un movimiento de masas que nunca hubiéramos soñado ni imaginado ni sabíamos que era eso. Entonces el movimiento del 68 es muy formativo, para toda la generación por supuesto, no sólo para nosotros. Pero los que éramos ya militantes políticos de la izquierda, pues fue una sacudida y una escuela nueva. Conocimos el país de otra manera [...] Y eso abrió, digamos, muchas relaciones entre los pocos estudiantes que después se van a consolidar como relaciones muy entrañables muy cercanas. ${ }^{8}$

El caso de Juan Manuel Aurrecoechea, otro joven que se integró a la organización semanas después de su constitución y que en ella participó en la elaboración de los periódicos que distribuían -La Causa del Pueblo y Trabajadores en Lucha-, es significativo en cuanto a la percepción del ambiente que se generó a partir de los sucesos represivos que acallaron al movimiento estudiantil y que en su caso lo llevarían a integrarse a la Cooperativa, considerándola una opción de acción en contraposición al estilo de vida estudiantil convencional:

Yo entonces estaba estudiando filosofía en la UNAM, y pues estábamos en la depresión del movimiento estudiantil después de la matanza del 10 de junio. Tomó una serie de perspectivas todo el sueño del 68 y del 71. Después de la represión como que se había vuelto todo muy depresivo y como que uno se preguntaba, qué sentido tiene estudiar filosofía, para qué, que chiste tiene. Parecía todo como hacer una carrera, como muy convencional, muy integrada al sistema, aunque fuera una escuela que era bastante crítica, como era la Escuela de Filosofía en esos años. Ya había, pues corrientes. Digo, había un auge del marxismo e incluso de otras filosofías. Pero de todas maneras a

${ }^{8}$ Pérez Arce, F. (2 de marzo de 2016). Entrevista a Francisco Pérez Arce/Entrevistador: Alonso Getino Lima, Ciudad de México.

\section{()(1) $(9$}


mí me parecía como que la escuela, la universidad, se había vuelto una cosa muy cerrada, como muy volcada hacia sí misma, con muy pocas perspectivas. Pues había también como las ganas de conocer el mundo y conocer otras experiencias. Y toda una corriente crítica de izquierda que decía: es que el movimiento estudiantil tiene que volcarse y fusionarse con los movimientos populares, con el movimiento obrero, con el movimiento campesino. Para que lo que hacemos sirva de algo y salirse un poco de la universidad. ${ }^{9}$

La importancia del movimiento estudiantil en la vida de los cooperativistas no se limitó al hecho de que varios de ellos tuvieron participación activa en él, adquiriendo experiencia como brigadistas y activistas estudiantiles, sino también porque tras los sucesos represivos del 2 de octubre de 1968 y del 10 de junio de 1971, se produjo un ambiente de incertidumbre, que a muchos de ellos los llevó, como a Aurrecoechea, a cuestionar sus propias perspectivas como estudiantes y a decidir incorporarse a la lucha social. Se trató de un periodo de ebullición política en el que diversos grupos compartieron el escenario social, convergiendo y divergiendo en postulados ideológicos y proyectos de futuro. Fueron años caracterizados por la proliferación de organizaciones de influencia trotskista, anarquista, guevarista y maoísta que cuestionaban el régimen de Luis Echeverría, marcado por la represión, el populismo y la cooptación. En el caso de la Cooperativa, los postulados maoístas de "ir al pueblo", inaugurados en México en 1968 con la aparición de "Hacia una política popular" de Adolfo Orive y Alberto Anaya, a su vez influenciados por la recepción de grupos franceses, en los que participaban Jean-Paul Sartre, Simone de Beauvoir y Jean-Luc Godard tuvieron la mayor resonancia (Puma, 2014, p. 22). La posterior transformación de la Cooperativa se explica en parte por estas concepciones, a la par del contexto convulso en el que se desarrolló; caracterizado por un auge de movilizaciones campesinas, urbano populares y laborales. A este asunto se pasará más adelante, por el momento toca hablar sobre las posturas cinematográficas de la organización.

9 Aurrecoechea, J. M. (12 de octubre de 2016). Entrevista a Juan Manuel Aurrecoechea/ Entrevistador: Alonso Getino Lima, Ciudad de México. 


\section{HACIA UN CINE "VERDADERAMENTE POLÍTICO”}

Cabe mencionar que en lo general, las posturas teóricas internacionales fueron factor importante en cuanto a las vías de acción elegidas por los jóvenes que decidieron articular la política con el arte. Dentro del teatro sobresalieron los planteamientos de Bertolt Brecht entorno al teatro épico, de Augusto Boal con respecto al teatro del oprimido y de Peter Weiss, representante del teatro documental. En el terreno cinematográfico las influencias se encontraban en el neorrealismo italiano, la nueva ola francesa, el cinema verité y el nuevo cine latinoamericano. Este último conformado por realizadores como Glauber Rocha, Fernando Solanas, Octavio Getino, Jorge Sanjinés, Julio García Espinosa y Ruy Guerra, repercutió especialmente en los primeros cooperativistas en cuanto sus concepciones del medio cinematográfico dentro de la sociedad.

Octavio Getino y Susana Vellegia explican la emergencia de este cine de manera continental, como resultado del contexto social y cultural del periodo en la región -iniciado con la revolución cubana y la filmación de Historias de la revolución por Tomás Gutiérrez Alea-, así como por la influencia ejercida por ciertos movimientos cinematográficos en los distintos realizadores latinoamericanos: documentalismo inglés, expresionismo alemán, cine soviético, cine de autor francés, cine japonés, neorrealismo italiano, realismo del cine estadunidense y latinoamericano, la emergencia del cine independiente $y$, en general, de los nuevos cines - free cinema, la nueva ola (Getino y Velleggia, 2002, p. 12). El movimiento del nuevo cine latinoamericano nunca despegó por completo en México; sin embargo, influyó a distintos cineastas y grupos como la Cooperativa de Cine Marginal y el Taller de Cine Octubre, quienes en particular se propusieron difundir y desarrollar este movimiento fílmico en el país.

Entre la gama de propuestas, las que mejor empataron con las posiciones y expectativas de los cooperativistas fueron las del realizador y teórico de cine cubano Julio García Espinosa sobre el cine imperfecto. García Espinosa propuso en 1969 en su ensayo "Por un cine imperfecto" la construcción de una nueva poética que lograra hacer del cine una actividad desinteresada, evitando la híperespecialización de quienes lo realizaban, que en esa lógica significaba caminar hacia la socialización del cine. La cuestión fundamental era lograr que el cine fuera elaborado por cualquier persona y no por autores en un sentido elitista, desvinculados de otras actividades sociales. Además, se trataba

\section{()(1) $(9$}


de una interpretación insertada en una lectura teleológica de la historia, que identificaba como ideal el advenimiento del socialismo. García Espinosa abogaba por un cine revolucionario en un amplio sentido. Es decir, no sólo en términos estéticos, sino también en cuanto a su papel dentro de la sociedad como agente de cambio. De manera que el objetivo último de los postulados teóricos del cineasta y de su práctica fílmica, estaban dirigidos a la construcción de una cultura nueva, ante lo cual el cine tendría que tener un carácter acorde.

El adjetivo "imperfecto" que le atribuye al cine, no tiene que ver de ninguna manera con un cine mal hecho o austero, en cuestión estética o técnica, sino con la concepción que el autor posee de la sociedad y del papel del arte en ella. Es decir, del deber ser del cine dentro de un mundo que camina hacia el socialismo. La noción que García Espinosa expresa sobre el arte en general, y el cine en particular, tiene en el centro el ideal de constituirse en "actividad desinteresada" - en el sentido de que no se busque con ella una realización personal del artista-. De manera que lograr esto significaría arribar a una "perfección" -en el arte y en el cine; el artista se concebiría a sí mismo como un hombre que "entre otras cosas" hace arte y no como un especialista, desvinculado de otros quehaceres-. En esta lógica, mientras no se llegue al estado descrito la situación del cine seguiría siendo "imperfecta".

La propuesta de García Espinosa apunta hacia la apertura del arte y del cine. Propiciando las condiciones para que los espectadores se conviertan en autores y el arte sea así una manifestación de todos los hombres por igual. El cine imperfecto que propone fungiría como enlace entre el cine espectáculo, de influencia estadunidense, en el que se concibe a los hombres como espectadores, y un futuro cine perfecto, totalmente democrático. Con respecto a las características de este apunta:

El cine imperfecto entendemos que exige, sobre todo, mostrar el proceso de los problemas. [...] Mostrar un proceso no es precisamente analizarlo. Analizar, en el sentido tradicional de la palabra, implica siempre un juicio previo, cerrado. Analizar un problema es mostrar el problema (no su proceso) impregnado de juicios que genera a priori el propio análisis. Analizar es bloquear de antemano las posibilidades de análisis del interlocutor. Mostrar el proceso de un problema es someterlo a juicio sin emitir el fallo. Hay un tipo de periodismo que consiste en dar el comentario más que la noticia. Hay otro tipo de periodismo que consiste en dar las noticias, pero valorizándolas mediante el montaje o compaginación del periódico. Mostrar el proceso de un

\section{()(1) $(9$}


problema es como mostrar el desarrollo propio de la noticia, sin el comentario, es como mostrar el desarrollo pluralista - sin valorizarlo- de una información. Lo subjetivo es la selección del problema condicionada por el interés del destinatario, que es el sujeto. Lo objetivo sería mostrar el proceso, que es el objeto (García, 1975, p. 50).

El núcleo de la propuesta de Espinosa estaba en la integración de los trabajadores, en su calidad de receptores, para completar los filmes mediante la discusión al final de cada película exhibida, posibilitando a su vez su preparación y figuración como realizadores de auténticas obras fílmicas. Tal postura era compartida por intelectuales como Chris Marker, Jean-Luc Godard y Susan Sontag. Esta última, en un encuentro que mantuvo en 1972 con algunos cooperativistas -Eduardo Carrasco Zanini, Paco Ignacio Taibo, Enrique Escalona, José Carlos Méndez, Carlos de Hoyos, Víctor Sanen-, después de presenciar algunos filmes de la organización -Víctor Ibarra Cruz, de Carrasco Zanini; El año de la rata, de Enrique Escalona; Ardiendo en el sueño, de Paco Ignacio Taibo y el Comunicado 2-, exhibió sus reflexiones sobre las posibilidades de un cine político en términos similares a los de Espinosa; identificando las limitantes de la producción del grupo y aseverando que la única forma de edificarlo sería logrando que los trabajadores construyeran sus propios discursos narrativos sin tener como intermediarios los criterios de los especialistas del cine. ${ }^{10}$ Los integrantes de la Cooperativa de Cine Marginal se mostraron receptivos en torno a las críticas de Sontag, haciéndolo evidente con su trabajo Panaderos -también referido como Con la venda en los ojos (Ayala, 1986, p. 380)-, en el que los trabajadores de una panadería de la ciudad de México realizaron el guion, manejaron las cámaras e interpretaron a todos los personajes. Se trató de la película de la Cooperativa con mayor propuesta narrativa, según Guadalupe Ferrer:

Había una película muy hermosa que se llamaba Panaderos que era una película muy bien contada, que es la historia de una huelga en una panadería chiquita y ahí además la experiencia fue muy buena porque los trabajadores hicieron el guion, escogieron la música pues eran los actores ya que era su lucha, su película y esta película realmente hubiera sido maravilloso poderla

${ }^{10}$ L. Terán, Susan Sontag dice que "Es muy difícil utilizar el cine como arma política", Excélsior, 18 de febrero de 1972.

\section{()(1) $(9$}


conservar junto con otras pero desapareció. [...]Panaderos era ficción. Aunque..., era ficción porque tenía características..., o sea, estaba construida en un lapso de tiempo, tenía una historia, metida que era, cómo eran los panaderos, cómo vivían. Pero, al final del día, ellos eran los panaderos de verdad. Estaban hablando de su propia historia y estaba armada como una ficción. ${ }^{11}$

Sin embargo, esa fue una experiencia aislada. La mayor parte de la producción fílmica de la Cooperativa fue constituida por los Comunicados de Insurgencia Obrera; producciones de corta duración realizadas con el objetivo de difundir las luchas que los trabajadores emprendían en distintas latitudes del país. Se buscaba con ello producir nuevos movimientos y alimentar moralmente los existentes en otros estados del país. Entre diciembre de 1971 y marzo de 1972 la Cooperativa realizó diez comunicados, llegando a 20 para mediados de aquel año. ${ }^{12}$ En este periodo, según Carlos Méndez se llevaron a cabo un promedio de catorce "proyecciones debate por semana" en la ciudad de México. Un suceso importante en la historia de la organización a este respecto fue la movilización del Sindicato de Trabajadores Electricistas de la República Mexicana (STERM) en diciembre de 1971, en el cual participaron y al que dedicaron varios de sus trabajos. Se trató del periodo de mayor actividad fílmica de la Cooperativa, el cual acabaría a inicios de 1973. Desafortunadamente, el mismo uso que se les dio a los comunicados hizo que se deterioraran al grado que la mayoría desapareciera, quedando menos de una decena completos, muchos sin sonido, y algunos fragmentos sueltos al resguardo de la Filmoteca de la UNAM. No obstante, hoy puede tenerse una idea del contenido de la mayoría de los comunicados gracias al estudio que Ayala Blanco realizó sobre la producción fílmica de la Cooperativa en los setenta (Ayala, 1986, p. 384).

\section{DISCUSIONES DENTRO DEL MUNDO DEL CINE}

La Cooperativa de Cine Marginal desde su constitución discutió con otras posiciones estéticas. Su mismo nacimiento derivó de una crítica a la con-

\footnotetext{
${ }^{11}$ Ferrer, G. (27 de enero de 2016). Entrevista a Guadalupe Ferrer/Entrevistador: Alonso Getino Lima, Ciudad de México.

${ }^{12}$ Méndez, J. C. Hacia un cine político: la Cooperativa de Cine Marginal. La Cultura en México. Suplemento de Siempre!, 19 de julio de 1972.
}

\section{()(1) $(9$}


cepción convencional de hacer cine experimental en México, evidenciada de manera explícita en 1961 en el comunicado del Grupo Nuevo Cine, constituido ese mismo año por José de la Colina, Salvador Elizondo, Rafael Corkidi, J. M. García Ascot, Emilio García Riera, Carlos Monsiváis, J. L. González de León, Gabriel Ramírez, José María Sbert, Luis Vicens, Julio Pliego, Paul Leduc y Alberto Isaac, entre otros intelectuales. En aquel documento se hacía un llamado a la constitución de una cultura cinematográfica en México que tuviera en el centro el "culto al autor": "el cineasta creador tiene tanto derecho como el literato, el pintor o el músico a expresarse con libertad. No lucharemos porque se realice un tipo determinado de cine, sino para que en él se produzca el libre juego de la creación, con la diversidad de posiciones estéticas morales y políticas que ello implica" (Manifiesto, 1988, p. 33).

Es importante mencionar que a su vez el Grupo Nuevo Cine había surgido como una impugnación a la crisis por la que atravesaba el cine mexicano a inicios de la década de los sesenta. En torno a este hecho Alma Rossback y Leticia Canel realizaron un preciso balance:

[...] los productores se retraían quejándose del gran número de películas enlatadas; los artistas, técnicos y manuales se hallaban desocupados; con frecuencia se oía hablar de una posible nacionalización del cine; se habían perdido los mercados cubano y venezolano y había dificultades con el chileno y el argentino. "El dinero que produce el cine no vuelve al cine", anotaba José de la Colina en un artículo. "Pero además, el cine mexicano ya no produce tanto dinero... Salen perdiendo, naturalmente los trabajadores y artistas del cine mexicano... El sindicato se convierte en un organismo cerrado que de hecho impide el ejercicio de la creación cinematográfica a quien esté fuera de sus filas y... [Mediante ciertos contratos] estipula la no exhibición de películas por gente fuera de esos sindicatos... Por ellos el cine se estanca... [Pero lo más importante] el cine mexicano ha venido bajando artísticamente... [Tal vez porque] el cine se hace por las mismas personas de hace 10, 20 años [...] (Rossback y Canel, 1988, p. 48).

Un enfoque similar al que los integrantes del Grupo Nuevo Cine tenían del medio audiovisual, resaltando la importancia del director en las obras, fue compartido años después por un grupo de jóvenes realizadores que en el primer concurso de cine Luis Buñuel (1970) se habían aglutinado en el Taller de Cine en $8 \mathrm{~mm}$ y que en el segundo evento entraron en confronta-

\section{()(1) $(9$}


ción con los integrantes de la Cooperativa de Cine Marginal debido a la cuestión del papel del público en el concurso -Alfredo Gurrola, Sergio García y David Celestinos-. Aquellos enfoques resultaron dos maneras encontradas de hacer cine.

Fueron evidentes en estas discusiones las reverberaciones de los fundadores del grupo argentino Cine Liberación, Octavio Getino y Fernando Solanas, en cuanto su taxonomía sobre los diferentes tipos de cine. Dicha postura estética y política estaba en el ambiente en México y algunos autores de la prensa del momento hicieron lecturas del conflicto acontecido en el segundo concurso de cine independiente en los términos de los intelectuales argentinos; viendo con el nacimiento de la Cooperativa de Cine Marginal el ansiado arribo del tercer cine al país: un cine enfocado en mostrar las causas de los problemas de los mismos espectadores, logrando con esto su participación en los debates y posterior "concientización". Un cine que a diferencia de un primer cine, enfocado en el ámbito comercial de las películas y un segundo cine; intelectual que fomentaba el culto al autor, aspirara a mostrar la "realidad sin eufemismos", luchando contra la despolitización y enajenación que las películas hollywoodenses y los medios de comunicación masiva del momento propiciaban. ${ }^{13}$

Por otra parte, los cooperativistas se concentraron en un cine que diluía la figura de autoría individual y en su utilización como herramienta informativa en un sentido más práctico, utilizándolo, a partir de su vinculación con el STERM en diciembre de 1971, como elemento de enlace mediante los aludidos "Comunicados de Insurgencia Obrera". En tal sentido sus expectativas con el cine como poética se vieron disminuidas y agotadas en muy poco tiempo. Este hecho provocó la salida de sus miembros con mayor interés en el medio audiovisual -Enrique Escalona, Eduardo Carrasco Zanini, Héctor Cervera-, sumándose a Gabriel Retes, quien abandonó la organización pocas semanas después de su constitución. Retes, en una entrevista que le realizó Arlene Lintz de Nava en 1975, sintetizó dicha postura:

Al principio estuve en el grupo que formó la Cooperativa de Cine Marginal. Salí de allí por diferencias de tipo ideológico. Yo pensaba, y sigo pensando, que el cine tiene que estar basado en una serie de principios técnicos, $y$ en un

${ }^{13}$ A. Garmendia, "El concurso de películas de 8 milímetros. ¿El camino hacia un 'tercer cine?'...”, Esto, 18 de agosto de 1971.

\section{()(1) $(9$}


regidor, un coordinador, un director, como lo quieras llamar, para que no sea tan anárquico. $\mathrm{O}$, a lo mejor, porque yo no era tan anárquico como ellos. Ellos no pensaban en el cine de autor. No creían en el cine argumental. Es el cine en el que yo creo. Ellos pensaban en el cine documental. Hubo diferencias de todo orden (Lintz, 1975, p. 55).

En tal sentido, la Cooperativa para nada fue un grupo homogéneo, sino por el contrario quienes la nutrían tenían diferentes concepciones, motivaciones y expectativas en cuanto a sus acciones con la organización. En un primer momento estas, en lo general, tenían relación con el cine. Se proyectaba en esos iniciales meses construir un circuito de exhibición y una red de distribución de las obras de los integrantes que habían participado en el concurso que le dio origen -Enrique Escalona, Eduardo Carrasco Zanini, Paco Ignacio Taibo, Gabriel Retes, Brigada Venceremos y El grupo-. Al respecto, Carrasco Zanini, autor de Víctor Ibarra Cruz, película premiada en aquel concurso y miembro fundador de la Cooperativa, recuerda:

hubo una tendencia o una influencia muy grande valorando la exhibición. $\mathrm{O}$ sea, nosotros teníamos esas cuatro películas originales [se refiere a Víctor Ibarra Cruz, de su autoría; El paletero, de Gabriel Retes; Sabrán de mí, de Enrique Escalona, y El día del asalto, de Paco Ignacio Taibo II], entonces, sí, pero hay que exhibirlas, que la gente las vea. Y entonces [...] nos organizamos, y eso fue muy padre, también para salir a exhibir. Es decir, como que una idea de ser de la Cooperativa era el proyector, no sólo la cámara, [...] es decir, no solamente es realizarlas, sino preocuparse por exhibirlas. ${ }^{14}$

Sin embargo, como se mencionó, la función social de las obras era concebida desde un inicio como una prioridad dentro de la organización. La opción de los cooperativistas por el medio cinematográfico versaba también en el hecho de que este era proyectado como una herramienta de politización con más efectividad que otras expresiones artísticas. Algunos integrantes del grupo, como el mismo Eduardo Carrasco Zanini, tenían la idea de que con

${ }^{14}$ Carrasco Zanini, E. (7 de enero de 2016). Entrevista a Eduardo Carrasco Zanini/Entrevistador: Alonso Getino Lima, Ciudad de México.

\section{()(1) $(9$}


él se abría la posibilidad de llegar a más gente que con otras prácticas como la música o el teatro. ${ }^{15}$

Tales reflexiones fueron las que lo motivaron a integrarse a la Cooperativa. El cine además era visto como una vía capaz de hacer cierto contrapeso a los medios de comunicación masiva del momento, concebidos por los cooperativistas como tendenciosos y poco apegados a la realidad de lo que estaba ocurriendo en el país. En tal sentido se entiende la intención de los integrantes de la organización en cuanto a la producción de notas informativas y su transmisión en distintos estados del país, mediante los "Comunicados de Insurgencia Obrera".

\section{DE CINE MARGINAL A LA MARGINALIDAD DEL CINE}

No obstante, las expectativas que mostró con respecto al cine Paco Ignacio Taibo II en un texto referente a la Cooperativa de Cine Marginal que escribió a principios de 1973, el trabajo de la Cooperativa fue tornándose más organizativo y menos apegado a la realización cinematográfica al transcurrir los meses (Taibo, 1973, p. 15). De manera que después de un periodo en el que la organización disminuyó la producción de películas, avocándose únicamente a su exhibición, el cine fue abandonado por completo a finales de 1973 por la Cooperativa. Sus miembros para entonces ya habían estrechado vínculos con otras organizaciones como el Frente Auténtico del Trabajo (FAT), el STERM y algunos abogados laboralistas como Armando Castillejos, Adela Salazar y Arturo Alcalde; lo cual les sirvió para vincularse con un mayor número de grupos de trabajadores y realizar otro tipo de acciones. En ese momento las expectativas de la Cooperativa de Cine Marginal se habían transformado, virando hacia la solución de problemas inmediatos en las distintas fábricas que visitaban y el asesoramiento de los trabajadores para exigir lo que merecían de acuerdo a sus posibilidades legales. Ya no se planeaba aquí transformar el mundo del cine ni siquiera ocuparlo como herramienta fundamental para la construcción de una nueva sociedad, acorde a las propuestas del Nuevo Cine Latinoamericano. La postura de los miembros de la organización en aquel

${ }^{15}$ Carrasco Zanini, E. (7 de enero de 2016). Entrevista a Eduardo Carrasco Zanini/Entrevistador: Alonso Getino Lima, Ciudad de México.

\section{(1)(1) $(9$}


momento subrayaba que lo fundamental para una transformación a largo plazo era la lucha en la cotidianidad, ocupándose de los problemas inmediatos de los trabajadores.

En este viraje, la renovación de sus integrantes, así como las experiencias durante los meses de trabajo de quienes permanecieron en la Cooperativa, tuvieron un papel fundamental. El contacto habitual con los trabajadores hizo que los cooperativistas hicieran a un lado las excesivas meditaciones sobre cuestiones teóricas y fueran adquiriendo mayor sensibilidad a los problemas reales de los obreros.

Así, la Cooperativa de Cine Marginal en los años que estuvo activa transitó este proceso de transformación. De ser una organización preocupada por la creación, distribución y exhibición de cine, pasó a ser una organización de activistas y asesores sindicales. Para entender con mayor profundidad este hecho resulta también importante la concepción que los cooperativistas tenían sobre el tipo de trabajo que hacían y que contraponían al de otros grupos de izquierda. El asunto principal era el dogmatismo y la ideologización. Al respecto, en distintas ocasiones los integrantes de la Cooperativa se pronunciaron en contra de fungir como intelectuales paternalistas, con respecto a los trabajadores. Siendo ellos quienes dictaran los lineamientos a seguir y las lecturas positivas del lugar de la clase obrera en la sociedad. Por el contrario, el interés de la organización era dar la palabra a los trabajadores. A esto se debió que en los periódicos que distribuían y en la mayoría de los Comunicados de Insurgencia Obrera tuvieran la intención de reducir al máximo su propia voz. Asumían los cooperativistas que su papel en las luchas era secundario, siendo su objetivo el estar al servicio de los obreros conectándolos entre sí y asesorándolos. Tal forma de trabajar, según integrantes de la organización-Santiago Flores, Francisco Pérez Arce-fue heredada de la Liga Comunista Espartaco, la cual después del movimiento estudiantil de 1968 había adoptado el postulado maoísta de trabajar mediante "línea de masas". Esto significaba entender que el pueblo era el protagonista de la historia y que la relación con los trabajadores tendría que ser horizontal. Algunos miembros de la misma Cooperativa habían sido miembros de la Liga. Tales fueron los casos de Paco Ignacio Taibo II, Santiago I. Flores y Francisco Pérez Arce.

La Cooperativa de Cine Marginal en su última etapa se centró en el acompañamiento de las huelgas acontecidas en la ciudad de México y en su

\section{()(1) $(9$}


periferia. Se organizó en grupos de trabajo por zonas de la ciudad y del Estado de México. David Arriaga al respecto recuerda:

Nunca me he puesto a hacer la cuenta pero había como cuatro grupos o cinco grupos. Por ejemplo, yo estaba en el grupo Xalostoc. Que ese, éramos, como diez, ocho o diez, que nos concentrábamos en trabajar en la zona industrial de Xalostoc, en Ecatepec. Y luego estaban los del grupo Iztapalapa, que trabajaban en esa zona, que también eran como cinco, seis, ocho; luego estaba gente que trabajaba con el fat, Frente Auténtico del Trabajo, que también tuvo un vigor y presencia muy fuerte en esos años. Otros estaban en el grupo Azcapotzalco, que trabajaban con compañeros de las fábricas de hierro, alineadoras, que producían botes. Gente del rastro de por ahí, de toda esa zona, donde ahora se encuentra la UAM. ${ }^{16}$

Finalmente, la Cooperativa se fue diluyendo, y desapareció en 1976. Se trató de una desfragmentación paulatina. Los cuestionamientos a los alcances de su trabajo en aquellos últimos meses de actividad eran constantes entre sus integrantes y en ocasiones se revalorizaron las posibilidades que hubiera tenido el haber seguido la vía cinematográfica para hacer política. ${ }^{17}$ Este camino sería retomado por otros grupos como Cine Canario Rojo, Colectivo Cine Mujer o Taller de Cine Octubre, quienes tuvieron como referente a la Cooperativa, y el trabajo que la organización en sus inicios había realizado.

\section{CONCLUSIÓN}

Considero que la reconstrucción de la historia de la Cooperativa de Cine Marginal no sólo es útil para al entendimiento de la historia del cine en México. Sino también para una mejor comprensión del México contemporáneo. Los

${ }^{16}$ Arriaga Weiss, D. (20 de abril de 2015). Entrevista a David Arriaga Weiss/Entrevistador: Alonso Getino Lima, Ciudad de México.

${ }^{17}$ Arriaga Weiss, D. (20 de abril de 2015). Entrevista a David Arriaga Weiss/Entrevistador: Alonso Getino Lima, Ciudad de México; Aurrecoechea, J. M. (12 de octubre de 2016). Entrevista a Juan Manuel Aurrecoechea/Entrevistador: Alonso Getino Lima, Ciudad de México; Ferrer, G. (27 de enero de 2016). Entrevista a Guadalupe Ferrer/Entrevistador: Alonso Getino Lima, Ciudad de México. 
sujetos que constituyeron la Cooperativa fueron producto de sus circunstancias históricas. El contexto en el que se desenvolvieron, marcado por lo que Ilán Semo denominó "el ocaso del mito" posrevolucionario y lo que Carlos Monsiváis refiere como el internacionalismo en la cultura, fue fundamental para su formación como actores sociales (Monsiváis, 1976, p. 193; Semo, 1989, p. 37). Sin embargo, resulta preciso analizarlos desde la historia social, partiendo del estudio de sus propias experiencias, para comprender sus procesos personales y evitar generalizaciones que los homogenice en demasía con otros proyectos políticos y, por el contrario, entender sus particulares expectativas en torno al papel del cine en la sociedad. Considero que se debe actuar de la misma manera para explicar la transformación de sus perspectivas y valorizaciones; que marcaron la transformación de la cualidad de su trabajo al grado de abandonar el medio audiovisual por completo. A mi parecer esto se debió a una jerarquización de las urgencias concebida al calor del trabajo cotidiano, a la recepción de las propuestas maoístas y a la renovación de los integrantes de la organización.

La Cooperativa de Cine Marginal desde su constitución hasta su fragmentación transitó por un proceso de transformación. De ser una organización enfocada en el mundo del cine; compuesta por jóvenes interesados en producir, exhibir y distribuir sus realizaciones, se convirtió en un grupo de activistas sindicales. Dicha transición ocurrió paulatinamente, hasta que la Cooperativa abandonó por completo el medio cinematográfico. En este trayecto, un evento trascendental en la historia de la organización fue la marcha convocada por el STERM, liderado por Rafael Galván, el 14 de diciembre de 1971 con el propósito de exigir la democracia sindical del sector. Fue en ese momento cuando la Cooperativa inició la realización de los "Comunicados de Insurgencia Obrera", con el propósito de informar, enlazar y provocar la movilización de los obreros y campesinos de distintas latitudes del país. Los cooperativistas fueron renunciando a sus proyecciones ideológicas a largo plazo y priorizando en el emprendimiento de acciones de apoyo inmediato a los trabajadores. El núcleo de estas era el asesoramiento en cuanto a estrategias de organización, la transmisión de experiencias en otros movimientos, y el apoyo legal.

Cabe mencionar que resulta difícil rastrear el momento conclusivo de la Cooperativa. Se trató de una fragmentación que tuvo relación con el final de la insurgencia obrera y la transformación de las circunstancias político-sociales del país a mediados de la década de los setenta. En aquel momen-

\section{()(1) $(9$}


to, mientras algunos miembros cuestionaron los alcances de sus acciones con la organización y decidieron emprender nuevos caminos; viendo agotadas las posibilidades del trabajo de la organización en su conjunto, otros continuaron realizando labores de activismo político durante muchos años más.

\section{LISTA DE REFERENCIAS}

Ayala Blanco, J. (1986). La búsqueda del cine mexicano (1968-1972). México: Editorial Posada.

Bartra, A. (2009). Tiempo de jóvenes. En S. Martínez de la Rocca (comp.), Voces y ecos del 68 (pp. 63-84). México: Miguel Ángel Porrúa.

García Espinosa, J. (1975). Por un cine imperfecto. En V.V. A.A., Cine y revolución en Cuba (pp. 37-53). Barcelona: Editorial Fontarama.

Gaytán Santiago, P. (2013). Información o el arte libertario de la información. En P. Gaytán Santiago, Guerra mediática prolongada. Emocracia, violencia de Estado y contrainformación (pp. 227-250). México: UAM-X.

Getino, O. y Velleggia, S. (2002). El cine de las "historias de la revolución”. Buenos Aires: Altamira.

Híjar Serrano, A. (comp.) (2007). Frentes, coaliciones y talleres. Grupos visuales en México en el siglo xx. México: ConAculta/Juan Pablos.

Hobsbawm, E. (1983). De la historia social a la historia de la sociedad. En Marxismo e historia social (pp. 21-44). Puebla: UAP.

Lintz de Nava, A. (1975). Entrevista con Gabriel Retes. Otrocine, I(1), 55-61.

Manifiesto del Grupo Nuevo Cine (1988). En Hojas de cine. Testimonios y documentos del nuevo cine latinoamericano (pp. 33-36). México: UAM.

Monsiváis, C. (1976). Notas sobre la cultura mexicana en la década de los setentas. En Cultura y dependencia (pp. 193-206). Guadalajara: Departamento de Bellas Artes del Estado (Colección textos latinoamericanos).

Puma Crespo, J. I. (2014). Populismo maoísta: un sendero que no condujo a la lucha armada. 1968-1979. (Tesis de maestría inédita). cide, México.

Quiroz Trejo, J. O. (2010). La izquierda mexicana: una nueva vieja izquierda. En J. O. Quiroz Trejo (comp.), Izquierdas: nuevas y viejas (pp. 73-104). México: UAM.

Rossback, A. y Canel, L. (1988). Los años sesenta: el Grupo Nuevo Cine y los dos concursos experimentales. En Hojas de cine. Testimonios y documentos del nuevo cine latinoamericano (pp. 47-56). México: UAM.

\section{()(1) $(9$}


Semo, I. (1989). El ocaso de los mitos (1958-1968). (México un pueblo en la historia, vol. 6). México: Alianza Editorial Mexicana.

Taibo, F. I. (1973). Extraños caminos de un cine del pueblo. México: Archivo personal Guadalupe Ferrer.

Thompson, E. P. (1981). Miseria de la teoría. Barcelona: Crítica.

Vázquez Mantecón, Á. (2012). El cine súper ocho en México. 1970-1989. México: Filmoteca UNAM.

\section{OTRAS FUENTES}

\section{Hemerografía}

Esto.

Excélsior.

Siempre! 